\section{CASE OF CYNANCHE TONSILLARIS:}

SUDDEN DEATH BY ASPHYXIA: PASSAGE OF THE PURULENT MATTER OF AN ABSCESS INTO THE LARYNX AND TRACHEA.

By William England, M.D., Wisbeach.

Mrs. B., aged 30, very handsome, of fair complexion, the mother of four healthy children, had a tardy con. valescence after accouchement in November, 1841. Although she had no cough she gained flesh but slowly, and in consultation with Mr. Burman, early in December, I was led to infer the existence of tubercular cachexia, and from stethoscopic examination, the probability of tubercular deposit in the right lung. After this threatened attack of phthisis Mrs. B. regained her usual health, with the exception of being thinner than prior to this accouchement. Since then she has had two children.

Sunday, August 12, 1849.-Mrs. B. got wet when walking with her husband. On the following day she suffered from sore throat, but having been subject to repeated attacks of quinsy for many years, and having always recovered from them without their being attended with dangerous symptoms, she refused having any medical assistance until a week after the commencement of the present attack.

Sunday, 19th, 2 P.M.-She was first seen by Mr. Burman, who found the case one of ordinary cynanche tonsillaris, and directed the frequent application of warm poultices to the external fauces, constant inhalation of the steam of warm vinegar and water, a gargle of infusion of roses with tincture of myrrh, and to take at bed-time a draught, with muriate of morphia a quarter of a grain; tartarized antimony, half a grain. The same evening the difficulty of deglutition was relieved.

Monday, 20th, 2 P.M.-Mrs. B. was much better, and the difficulty of deglutition continued to diminish. Repeat the draught at bed-time, and other treatment. Mr. Burman did not consider it necessary to repeat his visit in the evening. Before going to bed she ate some bread and milk for supper, and afterwards drank some wine whey. Her husband keeping one of the principal inns, Mrs. B. was as usual in the bar in the course of the evening.

Quarter to 11 P.M.-She went to bed, and was soon followed by her husband, who had wished her good night, and beard her response in a voice of her ordinary tone and strength, when she complained of faintness, from which she was relieved by her smelling bottle. In a few moments afterwards her husband was alarmed by a rattling sound in her throat, followed by instant suffocation. In less than a quarter of an hour Mr. Burman was at the bed-side, and found her sinking from asphyxia. On my arrival, in a minute or two, Mrs. B. was dead.

Tuesday, 21st.-Permission was given to inspect the larynx and trachea. After laying bare the whole surface of the vocal tube and trachea by a clean dissection of the external muscles, a longitudinal incision was made at once throughout its whole length from below upwards. As soon as the scalpel entered the trachea, a considerable quantity of sero-purulent matter gushed out, and as the incision was continued through the cartilages of the larynx, the whole of the tube, and particularly the sacculi laryngis, were found distended with flakes of pus floating in sero-sanions matter. The pus was the purulent matter of asthenic abscess, and not fetid. The mucous membrane sponged clean, presented a pale, uncongested, unphlegmasioid condition. The whole tube was in a state of integrity, without any perforation. The epiglottal aperture was. abnormally patent. Both tonsils were considerably enlarged, the right in a much greater degree than the left, which, by Mr. Burman's report, had much diminished in size since his first visit. Neither tonsils bad suppurated.

Remarks. - Nothing in medical statistics is better known than the extremely rare fatality of cynanche tonsillaris (quinsy.) Dr. Watson, in his excellent lectures, mentions only one unfavourable termination from his own personal knowledge, and which I shall presently allude to.

Dr. Gregory told the late Dr. Dnncan, jun., that among many hundred cases he met with only one that was fatal. Willan and Bateman, in their elaborate reports of the "Diseases of London," do not speak of any severe case of this form of angina. The only case that $I$ can find recorded that bears any analogy to the case of Mrs. B., is one published by Dr. Watson, in the third volume of the London Medical Gazette; but in that case the asphyxiating cause was coagulated blood from a branch of the lingual artery. being perforated by an abscess of the pharynx opening into the fauces below the left tonsil, on a level with the epiglottis. In the case of Mrs. B. also, the tonsils bad not suppurated, and I am inclined to think the abscess was plaryngeal, seated likewise under the left tonsil. 'That we were obliged to limit the postmortem inspection is much to be regretted.

Wisbeach, August 24, 1849.

\section{CLINICAL ILLUSTRATIONS.}

\section{MENORRHAGIA, UTERINE CONGESTION, \&C.}

By Edward Ballard, M.D., East Retford,

Late Senior Physician to the St. Pancras Royal General Dispensary, and Medical Tutor in University College, London.

Menorrhagia, pain, \&c.; difficult and painful micturition; enlargement of entire uterus; treatment by recumbency and bromide of potassium: recovery.

E. C., aged 28 years, married for five years to a footman who rarely visits her, by occupation a needlewoman, applied at the dispensary on February 17th, 1846. She bore a child about nine munths after her marriage, and nureed him eighteen months, by which she became very much debilitated. Immediately on weaning him she again became pregnant, and when about three months gone, after an accidental tripping, she miscarried, losing a large quantity of blood, and. 
becoming still more weakened. She kept her bed for the greater part of three months, suffering pain over the left hip and groin, and having an offensive red discharge. As she improved she went into the country for twelve months, during which time she was not visited by her husband, and the catamenial discharge occurred regularly, and in proper quantity. She returned home last June, and remained well till September, except that the catamenia did not appear during the months of July and August. On the 19th of September, however, she was poorly, and on the 22nd was suddenly seized with fainting, which was soon followed by cramp-like pains across the epigastrium, with tenderness. There was also severe pain across the loins. Bran poultices were applied, and she took some medicine. In three or four days afterwards very severe pain occurred over the right iliac crest, extending to the groin. In about a fortnight all the pains abated, and just as she was getting about again she was similarly attacked the second time with fainting, \&c., the pain running down the outside of the right thigh as far as the knee, and being much more severe than formerly. She was relieved by the opplication of a few leeches to the right side of the pubes, and a blister above the crest of the ilium.

From the 19th of September to the present time she has not been free for a day from a sanguinenus dis. charge, which, though thus constant, has been much greater at each catamenial period. For the last three months, moreover, she has suffered cutting pains across the hypogastrium, after passing her urine, or else a difficulty in the act, with frequency. About a fortnight ago she was suddenly seized with pain from over the right hip to the groin, which, coming at first in paroxysms, is now continual. During the same period she has been unable to lie on either side, since lying on the left side induces a sense of dragging from above the right hip, and from the narel when upon the right. The catamenial discharge has been very profuse for the last eight days, and accompanied by an abundance of clots; occasionally it appears to occur in gushes. Countenance pallid; frontal headache relieved by lying down; bowels regular. On pressing the lower part of the abdomen towards the inlet of the pelvis, a distinct resistance is met with. Further examination was postponed. She was directed to lie outside the bed con. tinually, with the hips slightly raised

The catamenial flow lessened shortly after retaining the posture directed, and on the 20th she stated that it had not been so trifing since her illness, and that the pains had also greatly diminished. On the 22nd it had completely disappeared, but not the pain and tenderness.

On the 25th the discharge not having returned, I made a physical examination. A hard tumour was very readily felt rising for about three inches above the pabes, in the middle line, rounded in outline, as if it were the fundus of the nterus. On vaginal examination the cervix was readily arrived at by the finger; it was enlarged and hard. The os uteri admitted the top of the finger, but had preserved its natural form. $A$ rounded tumour was perceived occupying the upper part of the pelvis, and plainly consisting of the enlarged body of the uterus. It was the first thing that the fingers touched on being introduced into the vagina, was rery hard, and could be moved by the finger within the vagina and the hand upon the tumour externally. She was directed to maintain as much as possible the recumbent posture, and to take three grains of bromide of potassium in infusion of ealumba three times a day.

She continued this treatment, with a slight intermission on account of some drspeptic symptoms, which had arisen, during nearly the whole time she was a patient at the dispensary. The pain soon began to lessen, and by the time the next catamenial period came rnund, which was on the 24th of March, it had completely disappeared. The discharge lasted a week, (the customary time for her,) was not profuse, and only a little clotted. On April 20th the catamenia returned, the flow again was natural, and on the 25th she went for a short time into the country, where, having given up the recumbency-she was out a great part of the day-the result of which was to induce a slight return of pain, and slight leucorrhca. On the 9th of May, having again been kept lving for four days, she was better in these respects, and experienced no difficulty or pain in passing her urine. I again made a physical exumination. The fundus, as felt. above the pubes, presented a smaller tumour, giving a less striking idea of hardness, and lay more towards the back part of the pelvis. The raginal examination exhibited the body of the womb smaller, but still forming a distinct tumour, more moveable. From this time she continued to gain strength, and on the 18th of June, when she was discharged, the body of the aterus was of little more than the ordinary size, and with the cervix sufficiently soft. The os remained still large and open. There bad been no pain, and the catamenia had just occurred, perfectly natural in every respect.

\section{REMARES.}

I have narrated this case, not because it presents anything of singularity in its pathology, or of novelty in its management, but because it enables me to make a few observations on a common form of a very common disease.

Whenever a case of menorrhagia presents itself for treatment, the inquiry naturally suggests itself, whether it is dependent on causes operating through the system generally, or whether it is to be attributed to some local affection of the generative organs. If on careful investigation we discover nothing in the general state of the constitution to account for it, the next point is to determine whether the uterus itself is in fault, and this should be done even where a sufficient cause is discovered in the state of the vascular system as to fulness, tonicity, \&c. Having settled upon the uterus as the seat of disease, the question arises whether it is of a temporary nature, such as a derangement in its vascular supply, or whether it is more permanent in its duration, as would be the case with cancer, fibrous tumour, polypus, \&c. This process, then, had to be 
gone through in the diagnosis of the case I have been relating. The patient was plainly debilitated. Here was a cause which might operate forcibly in the production of the symptoms we areconsidering; but on the first day she was visited, I detected a tumour extending some way above the level of the pubes, which led me to believe that there was in addition some local disorder, an opinion which was confirmed by the pains she suffered over the ilia and in the groins, the dragging sensations when lying on her side, and the disturbance of the functions of the bladder. Further evidence was afforded, on the cessation of the menorrhagic flow, by raginal examination. The entire organ was then found to be swollen, and it remained to determine the nature of the enlargement. Was it due to the development of fibrous tumours? If these were subserous, they cuuld not have been expected to produce menorrhagia, besides which the swelling would have been lobulated, not regular and uniform, as in the case before us. Submucous tumours, if numerous and of large size, are also disposed to produce elevations on the exterior of the organ, (see Case II.,) which were nct present here, the enlargement being general and uniform. The menorrhagia which leads to the suspicion of these growths, too, is in the form of a sudden and profuse flooding, occurring repeatedly after intervals of complete cessation, and not necessarily at the ordinary catamenial periods. In this case it was a mere increase in the natural discharge, with a protraction through the interval. It was just what might have been expected to oecur when the organ was loaded with blood, which the regular discharge, though augmented, was incapable of relieving. Was it cancer with hypertrophy, as in Case II.? The objections adduced to the idea of flbrous tamour hold good here also, besides which the patient was at a rather early age for that disease; the cervix was unaffected by any cancerous deposit, as is usually the case if the organ is affected with it at all; and when it affects the body only, it is mostly the posterior wall, of which there was no evidence. Pregnancy was entirely out of the question, the only point in its favour being the enlargement of the body of the womb, and the rounded anterior wall, as felt from the vagina, every other symptom and sign being opposed to it. It only remained for me to consider whether the womb were merely the seat of congestion, or whether there was any inflammatory action conjoined with it. The duration of the congestion rendered it not improbable, and although pathologically doubtful, yet considering that congestion of an organ rarely lasts long without an increasel deposition of nutritive plasma, it was practically proper to lean to the affirmative, at any rate to permit this bias to guide the treatment.

The cause of all the ailments the patient suffered from was the protracted lactation which followed the birth of her first child. This disposed the womb to suffer from gravitative congestion, without which the simple act of tripping in her walk would have been insufficient to occasion miscarriage. This was the time when she first began to complain of pain over the hip, and presented a sanguineous discharge. The illness, which had lasted for five morths when she came under my care, was due no doubt to gravitative canses, cooperating perhaps with a general reduction of the tone of the system on returning to London and her customary occupation. The recurrence of pain in the month of May, after it had disappeared nnder treatment, was also plainly the effect of giving up the recumbent posture she had been maintaining previously, and over exertion.

Believing, then, that I had to do with a menorrhagia, dependent on long standing congestion of the uterus, which was probably accompanied by an increased deposition of plasma, and that all was kept up by the influence which at first occasioned the disorder, namely, gravitation in a debilitated subject, I abstained from any local abstraction of blood, relying upon the fulfilment of the following indications:-lst, the removal of the influence of gravitation; 2nd, the improvement of the patient's strength; and, 3rd, the promotion of absorption of any deposited plasma, which congestion or inflammation might have given rise to: With a view to the first, she was kept in the recumbent posture, with the hips elevated by a pillow; to fulfil the second. she was supplied with a tonic infusion, and a liberal diet; and for the third, bromide of potassium was administered-a remed $y$ which has been believed especially applicable in cases of uterine disease. The good results which followed attested the correctness of $\mathrm{my}$ views. From the very day the patient assumed the recumbent posture, the menorrhagia lessened, and in five days, although of five months' continuance, it had entirely ceased. It took a longer time, however, for the enlarged vessels to assume their normal dimensions, and for the entire reduction of the bulk of the uterus.to be accomplisbed; the latter object was not completely attained even when the woman was discharged from the Dispensary, although she had been taking the bromide for four months with but brief intermissions. Her strength, however, had much increased, she was free from all uneasiness, there was a great reduction in the size of the womb, and the catamenia were in every respect regular.

\section{Toospital Reports.}

\section{QUEEN'S HOSPITAL, BIRMINGHAM.}

\section{CLINICAL REPORTS OF SURGICAL CASES}

\section{UNDER THE TREATMENT OF PROFESSOR}

\section{SANDS COX, F.R.S., SENIOR SURGEON TO} THE HOSPITAL.

Reported by Mr. Peter Hinckes Bird, late Resident Medical Officer.

\section{Case XXV.}

\section{ENCEPHALITIS FROM A BLOW ON THE HEAD.}

Mary Brown, aged 30, single, but has one child; a proprietor of a house of ill fame; a stout fine woman, but of intemperate habits. Admitted under the care of Professor Sands Cox, on the 27th December, with two 